\title{
"How many cardiac surgeons does it take to write a research article?": Seventy years of authorship proliferation and internationalization in the cardiothoracic surgical literature
}

\author{
P. Modi, MD, FRCS(CTh), A. Hassan, MD, PhD, FRCSC, C. J. Teng, MD, FRCSC, and \\ W. R. Chitwood, Jr, MD, FACS, FRCS(Eng)
}

From the East Carolina Heart Institute, Greenville, NC.

Received for publication Oct 26, 2007; accepted for publication Dec 3, 2007.

Address for reprints: P. Modi, MD, FRCS(CTh), East Carolina Heart Institute, The Brody School of Medicine, $248 \mathrm{Ed}$ Warren Life Sciences Building, 600 Moye Blvd, Greenville, NC, 27834 (E-mail: modip@ecu.edu).

J Thorac Cardiovasc Surg 2008;136:4-6

$0022-5223 / \$ 34.00$

Copyright $(\underset{0}{ } 2008$ by The American Association for Thoracic Surgery

doi:10.1016/j.jtcvs.2007.12.057
$\mathrm{P}$ ublications are the currency of academic medicine. ${ }^{1}$ They are proof of scholarly accomplishment and confer prestige, research funding, and academic promotion. Recent years have witnessed an increasing trend in multiauthor publications and a decrease in single- or dual-author articles in both the physical sciences ${ }^{2}$ and biomedical research. ${ }^{3}$ Internationalization of highly-rated US and British surgical journals has also become evident, with a marked increase in articles from Europe and Asia. ${ }^{4,5}$ The purpose of this study was to assess whether the changing trends in authorship and international contribution have been mirrored in the cardiothoracic literature over the last 70 years.

The archives of the Journal of Thoracic Surgery (now the Journal of Thoracic and Cardiovascular Surgery [JTCVS]) and the Annals of Thoracic Surgery (ATS) were searched from the first decade of publication (1936 and 1966, respectively) at 10-year intervals up to 2006 to record the number of authors for each original article. Additionally, the archives of the European Journal of Cardiothoracic Surgery (EJCTS) were searched from the first full year of publication (1987) and again in 1996 and 2006 for the same data. The geographic origin of each original article published in the first volume of the JTCVS every 10 years from 1936 through 2006 was also determined and categorized as either North America (US and Canada), United Kingdom, European Union, Far East (Japan and China), or "other." Articles arising from 2 or more of these were classified as multinational. Brief communications, letters, editorials, book reviews, and conference abstracts were excluded from the analysis. The following statistical tests were used to evaluate statistical significance. Differences in mean number of authors and geographic origin were analyzed by using analysis of variance and the $\chi^{2}$ test, respectively. All statistical analyses were performed with the SAS software package, version 9.1.3 (SAS, Cary, NC).

A total of 3669 articles were retrieved (JTCVS, $n=1634$; ATS, $n=1549$; EJCTS, $\mathrm{n}=486$ ). The mean number ( \pm standard error of the mean) of authors per article increased with time for all journals: from $1.4 \pm 0.1$ in 1936 to $7.5 \pm 0.2$ in 2006 for the JTCVS $(\mathrm{F}=188.6, P<.0001)$, from $3.1 \pm 0.2$ in 1966 to $6.8 \pm 0.1$ in 2006 for the ATS $(\mathrm{F}=129.5, P<.0001)$, and from $4.2 \pm 0.3$ in 1987 to $6.2 \pm$ 0.1 in 2006 for the EJCTS $(\mathrm{F}=23.8, P<.0001$; Figure 1$)$. The mean number of authors per article was higher in the JTCVS than in the ATS than in the EJCTS for 1986/1987, 1996, and $2006(\mathrm{~F}=7.8, P=.0005 ; \mathrm{F}=15.0, P<.0001$; and $\mathrm{F}=22.5, P<.0001$, respectively).

The proportion of single- and dual-author articles for all journals decreased over this time period, from $96.3 \%$ in 1936 to $3.2 \%$ in 2006 , whereas the proportion of articles with 6 or more authors increased from $0 \%$ in 1936 and 1946 to $73.9 \%$ in 2006 (Figure 2). Articles with 3 to 5 authors increased from 3.7\% in 1936 to $59 \%$ in 1966 and 1976, thereafter decreasing to 23\% in 2006.

With regard to geographic origin, 1042 articles were retrieved from the JTCVS (Figure 3). The proportion of articles from North America accounted for $96 \%$ of articles in 1936; however, these contributions decreased over time to $50 \%$ in 2006 , 


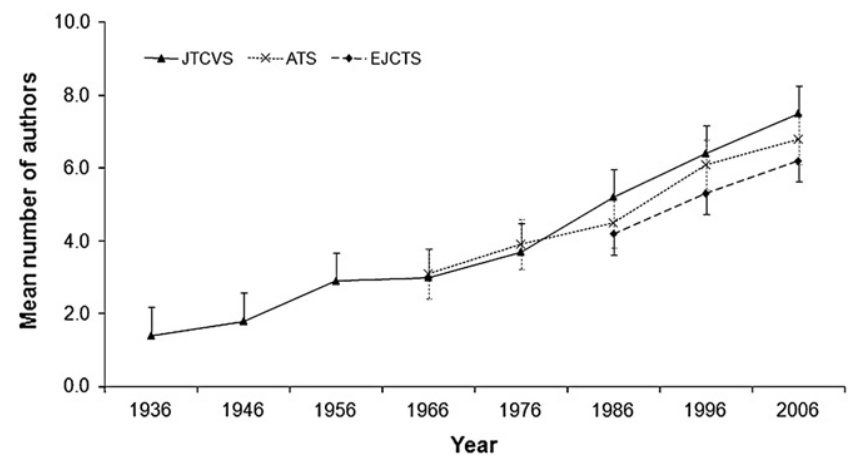

Figure 1. Mean number of authors per year (error bars indicate standard errors). JTCVS, Journal of Thoracic and Cardiovascular Surgery, ATS, Annals of Thoracic Surgery, EJCTS, European Journal of Cardiothoracic Surgery.

whereas contributions from Europe and the Far East increased. There was no consistent trend in the British contribution. The proportion of multinational articles increased significantly over time and accounted for $11.8 \%$ of original articles in 2006. Although there were minor differences in the mean number of authors per article between geographic regions in different decades, there did not appear to be any consistent trends (Table 1).

Examining more than 3650 articles published in the 3 leading cardiothoracic surgical journals over a 70 -year period, we found that the number of authors per original article has increased substantially; that single/dual authorship has all but vanished, with the majority of articles having 6 or more authors; and that the literature has become internationalized over time.

These trends are similar to those observed in the plastic surgery literature, which has seen a 3-fold increase in the mean number of authors between 1955 and 2005 from 1.7 to 4.2 in the Journal of Plastic and Reconstructive Surgery and 1.4 to 4.0 in the British Journal of Plastic Surgery. ${ }^{4} \mathrm{Sim}$ ilarly, the mean number of authors in the neurosurgical liter-

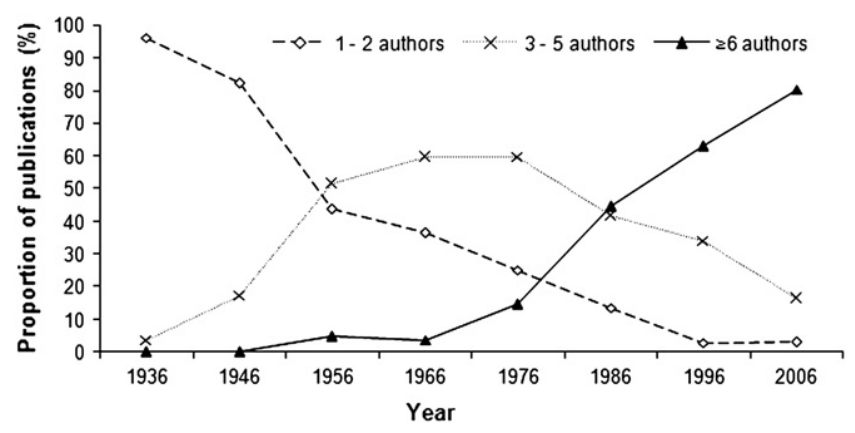

Figure 2. Changing patterns of publications with 1 to 2, 3 to 5 , and 6 or more authors with time.

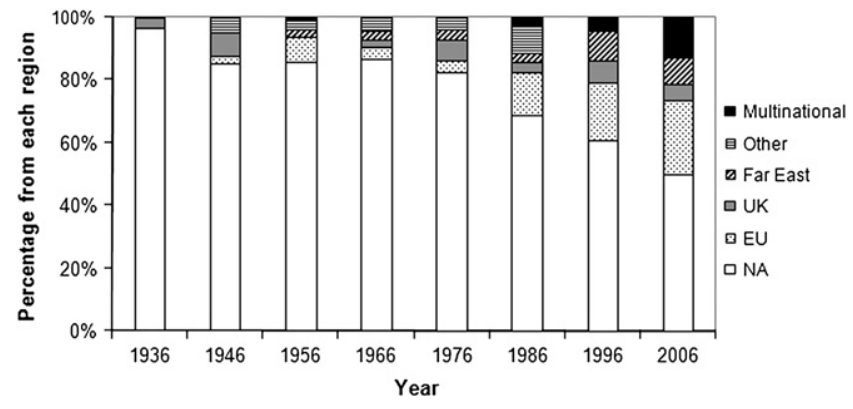

Figure 3. Geographic origin of articles in the Journal of Thoracic and Cardiovascular Surgery from 1936 through 2006. UK, United Kingdom; EU, European Union; NA, North America.

ature has gone from 1.8 in 1945 to 4.6 in $1995 .{ }^{5}$ Weeks and colleagues $^{3}$ assessed authorship in 4 prestigious medical journals (the Annals of Internal Medicine, the Archives of Internal Medicine, the Journal of the American Medical Association, and the New England Journal of Medicine) and found that the mean number of authors increased dramatically over time from an average of 4.5 in 1980 to 6.9 in 2000. In 12 leading radiology peer-reviewed journals over a 26-year period, the average number of authors doubled, from 2.2 in 1966 to 4.4 in $1991 .^{6}$

Multiple factors undoubtedly contribute to authorship proliferation. Modern scientific research is increasingly complex, with research teams typically composed of many individuals, each with particular skills. ${ }^{7}$ Multicenter, multinational collaboration, which requires the recruitment of sufficient patients in many centers (eg, large clinical trials), has also contributed where authorship is often bestowed as a reward for participation. Indeed, our data show that in 2006, $11.8 \%$ of original articles were multinational compared with 1936, 1946, 1966, and 1976, when 0\% were multinational. Furthermore, various support personnel, such as laboratory technicians or research assistants, might now be awarded authorship, whereas once they might have been simply acknowledged.

TABLE 1. Mean number of authors per country per year in the Journal of Thoracic and Cardiovascular Surgery

\begin{tabular}{lccccccc}
\hline & $\begin{array}{c}\text { North } \\
\text { Year }\end{array}$ & $\begin{array}{c}\text { United } \\
\text { America }\end{array}$ & $\begin{array}{c}\text { Europe } \\
\text { Kingdom }\end{array}$ & $\begin{array}{c}\text { Fart } \\
\text { Eather }\end{array}$ & Multinational & $\begin{array}{c}\boldsymbol{P} \\
\text { value }\end{array}$ \\
\hline 1936 & 1.4 & 0.0 & 1.0 & 0.0 & 0.0 & 0.0 & .30 \\
1946 & 1.8 & 2.0 & 1.0 & 0.0 & 1.5 & 0.0 & .51 \\
1956 & 2.9 & 2.3 & 0.0 & 7.0 & 2.0 & 1.0 & .01 \\
1966 & 2.9 & 4.5 & 2.0 & 4.3 & 3.0 & 0.0 & .04 \\
1976 & 3.7 & 3.8 & 3.7 & 3.4 & 1.8 & 0.0 & .12 \\
1986 & 5.1 & 5.7 & 5.0 & 4.7 & 5.6 & 3.7 & .81 \\
1996 & 6.6 & 6.6 & 5.7 & 6.6 & 5.0 & 6.8 & .88 \\
2006 & 7.9 & 7.7 & 6.9 & 7.2 & 6.5 & 8.1 & .81 \\
\hline
\end{tabular}


Competition for funding, the prestige of a sizable bibliography, and the emphasis placed on publication numbers by promotion and tenure committees are certainly major driving forces behind authorship proliferation. Others have suggested that "guest" or "gift" authorship (the act of including an individual who does not meet the authorship criteria specified by the journal) might be an important contributory factor, as a result of the academic pressure to "publish or perish." 8 This has been whimsically termed polyauthoritis giftosa. ${ }^{9}$ In fact, a survey of first authors of articles published in leading medical journals noted that a significant number of coauthors made little contribution to the work..$^{10}$ This practice diminishes the value of authorship because the presence of a name in the byline of a research article is no longer evidence of scholarly contribution. Authors who do not make a substantial contribution are unable to be held publicly accountable for the content, thus bringing into question whether all authors should be held responsible for the content given the often highly specialized roles of members of research teams. ${ }^{11}$

In an effort to define authorship, the International Committee of Medical Journal Editors (also known as the Vancouver group) have published regularly updated guidelines that were highlighted in an editorial by McKneally in JTCVS in $2006 .{ }^{12,13}$ The essential authorship criteria of the International Committee of Medical Journal Editors, all of which should be met, are as follows:

1. substantial contributions to conception and design, acquisition of data, or analysis and interpretation of data;

2. drafting the article or revising it critically for important intellectual content; and

3. final approval of the version to be published.

Authors should meet conditions 1, 2, and 3. Acquisition of funding, collection of data, or general supervision of the research group alone does not justify authorship. However, many researchers are ignorant of the criteria, ${ }^{14}$ and many find the criteria too rigid and inapplicable. ${ }^{15}$ Rennie and associates ${ }^{7}$ proposed replacing the current system of "authorship" with "contributorship," where contributors include all those who have added usefully to the work and a "guarantor" who takes overall responsibility for the work.

Authorship proliferation must be viewed with caution. Although it represents the changing face of clinical and basic science research and is unlikely to change, adoption of a "put me on that article" mentality undermines the integrity of both authors and journals. The academic cardiovascular community must take personal responsibility to ensure that authorship criteria as put forth by the International Committee of Medical Journal Editors are respected so that the highest ethical standards are maintained in our specialty.

In addition to the increasing number of authors per article, it is evident that the cardiothoracic surgical literature has become internationalized over time, particularly with increasing contributions from Europe and the Far East, paralleling trends seen in the highest-rated US and British anesthetic, plastic, and general surgical journals. ${ }^{4,16,17}$ This adds breadth and diversity to the scientific literature and might in part be attributed to the growth of the Internet in encouraging dissemination of these journals to a wider audience and the relative ease of online submission. Moreover, increased international contribution might reflect increased recognition of the journal, in terms of impact factor and reputation. ${ }^{4}$ Conversely, this can be viewed negatively as a proportionate decrease in US basic science research.

In summary, we have demonstrated that the cardiothoracic literature mirrors the general trend in authorship proliferation and internationalization seen in other branches of surgery and biomedical research in general. Original articles with 6 or more authors are now the norm, and the single/dual-author article has become all but a historical curiosity.

We thank Ms J. Floyd for data collection.

\section{References}

1. Lundberg GD. Publication and promotion. Writing is all. Lancet. 1998; 352:898.

2. Regalado A. Multiauthor papers on the rise. Science. 1995;268:25.

3. Weeks WB, Wallace AE, Kimberly BC. Changes in authorship patterns in prestigious US medical journals. Soc Sci Med. 2004;59:1949-54.

4. Durani P, Rimouche S, Ross G. How many plastic surgeons does it take to write a research article?"-authorship proliferation in and internationalisation of the plastic surgery literature. J Plast Reconstr Aesthet Surg. 2007;60:956-7.

5. King JTJ. How many neurosurgeons does it take to write a research article? Authorship proliferation in neurosurgical research. Neurosurgery. 2000;47:435-40.

6. Mussurakis S. Coauthorship trends in the leading radiological journals. Acta Radiol. 1993;34:316-20.

7. Rennie D, Yank V, Emanuel L. When authorship fails. A proposal to make contributors accountable. JAMA. 1997;278:579-85.

8. Bennett DM, Taylor DM. Unethical practices in authorship of scientific papers. Emerg Med (Fremantle). 2003;15:263-70.

9. Kapoor VK. Polyauthoritis giftosa. Lancet. 1995;346:1039.

10. Shapiro DW, Wenger NS, Shapiro MF. The contributions of authors to multiauthored biomedical research papers. JAMA. 1994;271:438-42.

11. Goldstein A. Collaboration and responsibility [letter]. Science. 1988; 242:1623.

12. International Committee of Medical Journal Editors. Uniform requirements for manuscripts submitted to biomedical journals. Updated February 2006. Available at: www.icmje.org. Accessed September 2007.

13. McKneally M. Put my name on that paper: reflections on the ethics of authorship. J Thorac Cardiovasc Surg. 2006 Mar;131(3):517-9.

14. Bhopal R, Rankin J, McColl E, Thomas L, Kaner E, Stacy R, et al. The vexed question of authorship: views of researchers in a British medical faculty. BMJ. 1997;314:1009-12.

15. Pignatelli B, Maisonneuve H, Chapuis F. Authorship ignorance: views of researchers in French clinical settings. J Med Ethics. 2005;31:578-81.

16. Tompkins RK, Ko CY, Donovan AJ. Internationalization of general surgical journals: origin and content of articles published in North America and Great Britain from 1983 to 1998. Arch Surg. 2001;136: $1345-52$.

17. Carnie J, Kumar B. An analysis of thirty years of contributions to the British anaesthetic literature (1953-1982). Br J Anaesth. 1984;56:1171-4. 